\title{
ALTERNATIVAS SUSTENTÁVEIS AO USO INTENSIVO DE AGROTÓXICOS NA AGRICULTURA BRASILEIRA
}

\author{
Jefferson Pereira da Silva Castro ${ }^{1}$ \\ Samuel Carvalho De Benedicto ${ }^{2}$ \\ Cibele Roberta Sugahara ${ }^{3}$ \\ Cândido Ferreira Silva Filho ${ }^{4}$
}

\begin{abstract}
Resumo
O uso demasiado de agrotóxicos na agricultura, no que se refere ao tipo e à quantidade de substâncias, nem sempre leva em consideração os danos gerados para a saúde, a sociedade e os ecossistemas. Este trabalho objetiva discutir sobre o uso permissivo de agrotóxicos no Brasil, apontar consequências geradas para os ecossistemas e indicar alternativas que sejam menos nocivas ao meio ambiente e à saúde. A partir de pesquisa bibliográfica, este ensaio permite indicar alternativas que podem subsidiar condições mais sustentáveis para a agricultura brasileira. A tecnologia de precisão e a agroecologia aplicadas à produção agrícola minimizam os impactos negativos ao meio ambiente e à sociedade. Os resultados sugerem que a efetividade de discussões políticas sobre os níveis de componentes agrotóxicos usados na agricultura brasileira é essencial para a proposição de regulamentação e práticas que resultem em um agroecossistema produtivo e ecologicamente responsável. No entanto, a permissividade do Estado brasileiro quanto ao uso de substâncias agroquímicas parece gerar problemas imensuráveis para a flora e fauna. No Brasil, a concessão de isenções fiscais e tributárias para a comercialização de alguns agrotóxicos que são banidos na União Europeia denota a pouca importância dada às implicações para a saúde humana e para o bioma brasileiro.
\end{abstract}

Palavras-chave: Estado brasileiro. Agricultura. Uso de agrotóxicos. Alternativas sustentáveis. Agroecologia.

1 Mestre em Sustentabilidade pela Pontifícia Universidade Católica de Campinas (PUC-Campinas). Analista de sustentabilidade da Tetra Pak. E-mail: castro.jep@gmail.com

2 Doutor em Administração pela Universidade Federal de Lavras (UFLA). Professor, Pesquisador e Coordenador do Mestrado em Sustentabilidade da Pontifícia Universidade Católica de Campinas (PUC-Campinas). Membro do Grupo de Pesquisa Gestão Estratégica e Sustentabilidade. E-mail: samuel.benedicto@puc-campinas.edu.br

3 Doutora em Ciência da Informação pela Universidade de São Paulo (USP). Professora e Pesquisadora da Faculdade de Administração e do Programa de Mestrado em Sustentabilidade da Pontifícia Universidade Católica de Campinas (PUC Campinas). Membro do Grupo de Pesquisa Gestão Estratégica e Sustentabilidade.E-mail: cibelesu@puc-campinas.edu.br 4 Doutor em Ciências Sociais pela PUC-SP. Professor e Pesquisador do Centro de Economia e Administração da Pontifícia Universidade Católica de Campinas (PUC-Campinas). Membro do Grupo de Pesquisa Organizações, Gestão e Sociedade. E-mail: candidofilho@puc-campinas.edu.br 


\section{Introdução}

O uso intensivo de agrotóxicos para o controle de doenças das lavouras e pragas tem demandado a atenção de instituições de pesquisa e organismos da sociedade civil que se debruçam em busca de uma alternativa economicamente viável e ambientalmente sustentável para essa atividade. Boff (2012) destaca que a agricultura moderna se originou como atividade no pós-guerra, no momento em que a indústria química produtora de agrotóxicos, os quais eram utilizados como armas, voltou-se para a agricultura com o objetivo de angariar este novo mercado para os seus produtos.

Durante os primeiros anos do século 21, as monoculturas aumentaram significativamente em todo o mundo. Dos 1,5 bilhão de hectares de terras agrícolas do mundo, $91 \%$ são dedicados às monoculturas extensivas de milho, soja, arroz, trigo e outros. Com a expansão da agricultura industrial, a diversidade de culturas por unidade de terra cultivável diminuiu e o uso de terras agrícolas se intensificou com uma tendência à concentração nas mãos de alguns produtores e, em particular, de grandes empresas (ALTIERI, 2009).

As tecnologias que tradicionalmente favoreceram a transição para a monocultura são: a mecanização, o melhoramento genético de variedades modernas e o desenvolvimento de fertilizantes e agrotóxicos para controle de pragas e ervas daninhas. Além disso, as políticas comerciais governamentais das últimas décadas promoveram a aceitação e o uso dessas tecnologias. De modo que, hoje, a biotecnologia transformou-se no motor da intensificação da agricultura industrial (ALTIERI, 2009).

Cada vez mais fica evidenciado que não há viabilidade na produção de grandes áreas de monoculturas sem o uso intensivo de insumos químicos, sobretudo, de agrotóxicos (MARIYONO et al., 2018). Porém, o agronegócio tem sido cada vez mais beneficiado pela leniência e omissão do Estado, por meio de benefícios auferidos com a justificativa de que o bem do agronegócio é de interesse nacional e, por conta disso, os grandes produtores rurais são privilegiados por medidas que, frequentemente, dão margem para desmatar florestas, contaminar solo, água, prejudicar a saúde dos trabalhadores do campo, entre outras (LEAHY; SCHIPANI, 2018).

Toda estrutura demandada para manter esse modelo de produção tem submetido o campo à visão mercadológica e tratado a agricultura familiar como não competitiva, atrasada e empírica. $\mathrm{O}$ resultado desse modelo é a redução de tudo o que está envolvido em capital e mercadoria, inclusive a natureza, tratada como capital natural, serviços ambientais, bionegócios etc. Desse modo, grande parte da produção das grandes propriedades está voltada para commodities, como milho, soja e cana-de-açúcar; produtos usados para alimentação animal, combustível ou exportação. Não se 
enfatiza, desta forma, a produção de alimentos que atendam aos hábitos alimentares da população, os quais, na maioria das vezes, são supridos por produtores familiares (WARMLING; MORETTI-PIRES, 2017).

O Estado, no sentido do conjunto de estruturas institucionais que asseguram a ordem e o controle de uma nação, tem como missão garantir a ordem da oferta de alimentos e, de certa forma, da economia, já que a agropecuária tem sido importante na balança comercial como grande exportadora de commodities, beneficiando o agronegócio, este que, grosso modo, representa toda a cadeia envolvida com a agropecuária (MENDONÇA, 2015).

É possível constatar que diversas políticas são instituídas com a finalidade de alavancar o agronegócio, que pode ser definido, na acepção brasileira, como a associação do grande capital agroindustrial em conjunto com a grande propriedade fundiária. Tal associação cumpre uma estratégia econômica de capital financeiro, perseguindo o lucro e a renda da terra, sob patrocínio de políticas de Estado (DELGADO, 2013). No Brasil, a maior expressão desse movimento se dá na bancada ruralista. $\mathrm{E}$, nas últimas legislaturas, houve uma significativa elevação da quantidade de membros da bancada ruralista no Congresso Nacional. Na legislatura 2011-2014, eram 167 parlamentares (deputados e senadores). A bancada ruralista na legislatura 2015-2018 conta com 228 parlamentares, representando 44\% da câmara dos deputados e 25\% do senado (LEAHY; SCHIPANI, 2018).

Essa concentração confere grande poder de barganha aos defensores do agronegócio, e esse poder costuma ser usado com medidas que prejudicam o meio ambiente, comunidades indígenas, quilombolas e os pequenos agricultores rurais. $\mathrm{E}$ tal poder pode ser visto na influência que esses governantes possuem sobre os atos do presidente da república, já que,em 2017, foram aprovadas 16 das 17 propostas elaboradas pela bancada. Além disso, a fiscalização que visa a mitigar o desmatamento tem se reduzido nos últimos anos, visto que entre 2010 e 2016 o número de agentes de fiscalização do Instituto Brasileiro do Meio Ambiente e dos Recursos Naturais Renováveis (IBAMA) foi reduzido em 26\% (LEAHY; SCHIPANI, 2018).

A crítica ao agronegócio ocorre, sobretudo, em razão do modelo de negócio, que busca o constante aumento da produção, o que é normal em um sistema capitalista, mas os meios utilizados para tanto são controversos, pois ocorrem, com frequência, através do desmatamento de áreas verdes, da contaminação do solo e da água, e da exploração do trabalhador rural. Isso torna esse modelo de negócio insustentável ambientalmente e socialmente (OLIVEIRA et al., 2016).

Cada vez mais as grandes corporações globais - que comercializam commodities alimentícias, agrotóxicos e outros insumos e equipamentos para o agronegócio -, além das bolsas de mercadorias e futuros, aumentam 
seu poder econômico e sua influência. É preocupante como isso se reflete no mercado de alimentos, na relação com os pequenos agricultores e até mesmo na influência que exercem sobre as políticas públicas, através do lobby (CASTRO, 2018).

Este trabalho objetiva discutir sobre o uso permissivo de agrotóxicos no Brasil, apontar consequências geradas para os ecossistemas e indicar alternativas que sejam menos nocivas ao meio ambiente e à saúde.

O estudo contempla uma reflexão teórica sobre a regulação e o uso de agrotóxicos em monoculturas e aos efeitos danosos que o uso indiscriminado gera ao meio ambiente. Tomando como base os princípios teóricos da agroecologia que comportam os sistemas orgânicos de produção (ASSIS; ROMEIRO, 2002). Apresenta alternativas de prática agrícola com o uso de tecnologia de precisão, sementes revestidas com micróbio, fungos nas raízes das plantas como meios para o equilíbrio ecológico de lavouras agrícolas. Nesse sentido, aponta a agroecologia como uma alternativa sustentável para a promoção da saúde e uso racional de recursos naturais.

Segundo Vilaça (2010), em termos gerais, são consideradas pesquisas teóricas aquelas que têm por finalidade: conhecer, aprofundar, discutir e criticar um assunto considerado importante e controverso. Para Tachizawa e Mendes (2008), uma pesquisa teórico-crítica, em geral, busca compreender ou proporcionar um espaço para discussão de um tema ou uma questão intrigante da realidade, sem requerer coleta de dados e pesquisa de campo.

O texto está estruturado em quatro partes além desta introdução. A segunda parte apresenta as políticas regulatórias para o uso de agrotóxicos na agricultura. $\mathrm{Na}$ terceira parte, é realizada uma discussão sobre a Revolução Verde e o agronegócio. $\mathrm{Na}$ quarta, são apontadas algumas tecnologias sustentáveis aplicadas à agricultura. $\mathrm{Na}$ quinta são apresentadas vertentes sustentáveis para a agricultura. E, na última parte, são feitas as considerações finais.

\section{Políticas regulatórias e o uso de agrotóxicos na agricultura brasileira}

A humanidade está se conscientizando do fato de que o atual modelo de produção agrícola não é suficiente para fornecer os alimentos necessários e, ao mesmo tempo, preservar a natureza. A expansão das terras agrícolas para biocombustíveis ou transgênicos cobrem mais de 120 milhões de hectares e exacerba os impactos ecológicos de monoculturas que ameaçam a biodiversidade e degradam a natureza (ALTIERI, 2009).

O agronegócio pode ser compreendido como um modelo de produção agrícola hegemônico, voltado para a monocultura, o predomínio da utilização de insumos químicos, o latifúndio, os equipamentos tecnológicos, as sementes e mudas geneticamente modificadas, a descaracterização da biodiversidade local e plantações uniformes (OLIVEIRA; PAULA, 2016). 
No agronegócio, o uso indiscriminado de agrotóxicos é uma questão latente. Este uso é danoso ao meio ambiente, por gerar contaminação da água, do solo e do ar, da eliminação das abelhas e outros polinizadores, e problemas de saúde aos trabalhadores do campo e consumidores que ingerem alimentos cultivados com substâncias impróprias (BARRETO et al., 2012).

A decisão em relação à escolha, à quantidade e à qualidade de agrotóxicos nem sempre é tomada considerando os danos de seus componentes químicos para a saúde, a sociedade e os ecossistemas, mas sim a partir de uma visão limitada de retorno de curto prazo (PORTO; MILANEZ, 2009).

É importante destacar que o aumento da quantidade usada é um "ciclo vicioso". De acordo com os dados do Departamento de Meio Ambiente do governo dos EUA, é constante a prática de aumentar a aplicação de substâncias químicas nas lavouras (VAZ, 2006). Vaz (2006) ressalta que, na década de 1970, os agricultores norte-americanos usavam 25 mil toneladas de agrotóxicos e perdiam 7\% da lavoura antes da colheita. No final da década de 1990, usavam 12 vezes mais agrotóxicos e perdiam o dobro. Isso ocorreu em decorrência das pragas agrícolas possuírem a capacidade de desenvolver resistência aos agrotóxicos aplicados; afinal, com o tempo, os agrotóxicos perdem a eficácia e, por consequência, os agricultores aumentam as doses aplicadas ou recorrem a novos produtos.

Entretanto, foi comprovado a partir de pesquisas que é tecnologicamente viável reduzir o uso de agrotóxicos na agricultura. $\mathrm{Na}$ Europa, como no caso da Dinamarca, em 1985, foi desenvolvido um plano de ação que visava a reduzir o uso de agrotóxicos em 50\% antes de 1997. Na Suécia, em 1988, foi aprovado um programa para reduzir o uso em 50\% em até cinco anos. Estudos e práticas como estas, mostram que se o uso de agrotóxicos fosse reduzido pela metade, não causaria qualquer declínio no rendimento da safra e o aumento total de preço na compra de alimentos seria em torno de $0,6 \%$, em decorrência do aumento dos custos de controles alternativos (PIMENTEL et al., 2001).

No início da década de 1990, o uso de agrotóxicos era financeiramente rentável, por auferir entre US\$ 3 e US\$ 5, para cada US\$ 1 investido no uso dessas substâncias. Todavia, esses valores não evidenciam os custos das externalidades negativas provocados pelo uso, como: intoxicações em humanos, redução da população de peixes e animais selvagens, destruição de culturas e vegetação, perdas de gado, destruição de inimigos naturais, aumento da mortalidade de abelhas, e, ainda, podem levar à resistência e à criação de problemas secundários de pragas. Portanto, os benefícios e custos diretos e indiretos do uso de agrotóxicos na agricultura são altamente complexos (PIMENTEL et al., 2001). 
Estudos que discutem os efeitos de alimentos orgânicos na saúde da população são escassos. Um estudo recente sobre o tema, publicado em 2016, pelo Parlamento Europeu, apresenta os benefícios dos alimentos cultivados sem agrotóxicos em comparação aos que são cultivados com o uso de agrotóxicos. O objetivo é fornecer informações sobre como a agricultura biológica e os alimentos podem contribuir na melhoria da saúde humana além de despertar a atenção para ações políticas, conforme European Parliamentary Research service (EPRS, 2016).

A pesquisa do European Parliamentary Research Service é importante como base para as negociações de um novo regulamento em discussão na União Europeia (UE), sobre a rotulagem dos produtos biológicos. Nesse sentido, está em discussão uma política mais rigorosa em relação aos resíduos de agrotóxicos em produtos orgânicos (EPRS, 2016).

É relevante destacar que desde 2011 está em vigor na União Europeia um marco regulatório mais restritivo para os agrotóxicos, tornando uma série de ingredientes ativos banidos ou em fase de banimento na região. As medidas trazem implicações para as indústrias de agrotóxicos instaladas no Brasil, ao passo que as empresas multinacionais tendem a direcionar parte da sua produção aos mercados menos restritivos (PELAEZ et al., 2015, p. 156).

Essa realidade denota uma contradição de que uma parte desses agrotóxicos retorna aos países-sedes das indústrias que os fabricam, por meio de alimentos que importam do Brasil (BOMBARDI, 2017).

Entre os resultados da pesquisa do European Parliamentary Research Service, destaca-se a indicação de que os alimentos orgânicos reduzem o risco de alergia em crianças e diminuem a incidência de obesidade entre os adultos. Além disso, constatou-se que o uso prolongado de fertilizantes minerais à base de fósforo contribui para o aumento das concentrações de cádmio em solos agrícolas. Este fato é altamente relevante para a saúde humana, considerando que a alimentação é a via dominante da exposição humana ao cádmio em não fumantes. A exposição atual da população a esse componente químico está próxima, e em alguns casos acima, dos limites toleráveis (EPRS, 2016).

Outro importante estudo, realizado por Brantsaeter et al. (2015), analisa a relação existente entre a incidência de alergias e os alimentos cultivados com agrotóxicos, tendo como amostra um grupo com mais de 28.000 mulheres grávidas com filhos nascidos entre 2002 e 2008. O trabalho buscou identificar a frequência do consumo de alimentos orgânicos das mulheres participantes. Entre as que relataram consumo frequente de vegetais orgânicos (mas não outros grupos de alimentos), houve uma redução de $21 \%$ no risco de pré-eclâmpsia, que é uma desordem que ocorre durante o terceiro trimestre da gravidez, caracterizada por pressão 
arterial elevada e uma grande quantidade de proteína na urina. Alguns casos podem ser graves, ameaçando tanto a mãe quanto o feto e levando ao nascimento prematuro. Conquanto, em um pequeno número de casos, este estudo também revelou evidências da ligação entre o consumo de alimentos orgânicos com o risco menor de hipospadias, mas não criptorquidismo (ambos defeitos congênitos em genitais masculinos).

A pesquisa do European Parliamentary Research Service também apresenta relevância ao retratar a relação entre o consumo de alimentos orgânicos e o risco de câncer. $\mathrm{O}$ estudo foi realizado com um grupo de pessoas composto por 623.080 mulheres de meia-idade do Reino Unido, durante um período de acompanhamento de 9,3 anos. A partir de um questionário (com três opções de resposta - nunca, às vezes ou geralmente e/ou sempre) os participantes relataram a frequência do consumo de alimentos orgânicos. $\mathrm{O}$ risco geral de câncer não foi associado ao consumo de alimentos orgânicos, mas observou-se uma redução significativa (-21\%) no risco de linfoma não Hodgkin (EPRS, 2016).

Os resultados da pesquisa revelaram também que existe uma ligação potencial entre as preferências por alimentos orgânicos e o linfoma não Hodgkin, o que poderia ser interpretado à luz dos resultados de uma meta-análise recente baseada em 44 estudos originais, e estes relatavam a exposição ocupacional a agrotóxicos, incluindo fenoxi herbicidas e inseticidas (carbamato, organofosforados e lindano) estava positivamente associada ao risco de linfoma não Hodgkin. O linfoma de células B também foi positivamente associado com a exposição ao herbicida glifosato e fenoxi (EPRS, 2016).

Apesar da escassez de estudos que investigam os potenciais efeitos benéficos do consumo de alimentos orgânicos comparados aos convencionais na saúde, por meio de uma estimativa direta de consumo, pode-se constatar que as poucas pesquisas, como as citadas nesta seção, têm demostrado que alimentos cultivados com substâncias agrotóxicas são maléficos à saúde humana.

Atualmente, 389 substâncias são autorizadas como pesticidas na UE. Destas, 35 também são aprovadas para uso na agricultura orgânica. Porém, grande parte das substâncias usadas para controle de pragas aprovada para a agricultura orgânica tem preocupação toxicológica comparativamente baixa para os consumidores, porque elas não estão associadas a qualquer toxicidade identificada (por exemplo: óleo de hortelã, areia de quartzo e alguns micro-organismos), visto que fazem parte de uma dieta normal ou são nutrientes humanos, tais como: ferro, bicarbonato de potássio e óleo de colza. Em outros casos, os pesticidas são aprovados para uso em armadilhas para insetos e, portanto, não são aplicados no solo ou nas plantas (EPRS, 2016). 
No Brasil, em 2018, estavam registrados 1.945 agrotóxicos para comercialização, sendo 504 ingredientes ativos. Dentre os componentes agrotóxicos citados no relatório, ressalta-se que todos são classificados como danosos à saúde humana, com exceção apenas do lindano. Portanto, todos os outros - por exemplo, fenoxi herbicidas, inseticidas carbamato e organofosforados - estão liberados para uso. O inseticida organofosforado é o segundo agrotóxico químico mais consumido no Brasil. Apenas em 2013, o consumo foi de 79.293 toneladas deste produto. Já o inseticida carbamato está na sexta colocação da lista dos mais consumidos no ano de 2013, com o consumo de 41.421 toneladas (BRASIL, 2016; BRASIL, 2018).

Entretanto, ressalta-se que, dos ingredientes ativos liberados para uso no Brasil, 149 estão proibidos na União Europeia. Isto é, 30\% de todos os ingredientes ativos liberados para uso no Brasil não podem ser usados em países da União Europeia (BOMBARDI, 2017).

Em 2016, a Agência Nacional de Vigilância Sanitária (ANVISA) divulgou um relatório elaborado pelo Programa de Análise de Resíduos de Agrotóxicos em Alimentos (PARA), com pesquisa realizada no período de 2013 a 2015, na qual foram monitorados níveis de componentes agrotóxicos em 25 alimentos, abrangendo as seguintes categorias: cereais/leguminosas, frutas, hortaliças folhosas, hortaliças não folhosas e tubérculos/raízes/ bulbos. Foram analisadas 12.051 amostras, e em 58\% delas foram detectados resíduos, considerando os agrotóxicos pesquisados (BRASIL, 2016).

Os resultados do Programa de Análise de Resíduos de Agrotóxicos em Alimentos reforçam o alto nível de agrotóxicos consumido no Brasil. Chama a atenção a diferença significativa entre o uso de agrotóxicos no Brasil e na União Europeia. Na União Europeia, o uso varia entre 0 e 2 $\mathrm{kg}$ de agrotóxicos por hectare. No Brasil, apenas para o uso de glifosato, agrotóxico mais consumido no País, tem-se, por exemplo, para os estados de Minas Gerais, Bahia, São Paulo e Mato Grosso do Sul uma média entre 5 a $9 \mathrm{~kg}$ por hectare. Nos estados do Rio Grande do Sul, Goiás e Mato Grosso o uso é de 9 a $19 \mathrm{~kg}$ por hectare (BOMBARDI, 2017).

O Limite Máximo de Resíduos (LMR) de agrotóxicos permitido no Brasil costuma ser bastante superior ao que é permitido na União Europeia. Atendo-se apenas ao LMR do glifosato, constata-se que o nível de permissividade para o uso desta substância no Brasil é assustador. Exemplo disso é o LMR aceitável na água "potável" brasileira, que é 5.000 (cinco mil) vezes superior ao LMR permitido na União Europeia (BOMBARDI, 2017). Como é possível ver no Quadro 1, o LMR permitido na produção de algumas culturas também é bastante diferente, sendo o Brasil mais permissivo. 
Quadro 1 - Comparação entre o Limite Máximo de Resíduos (LMR) permitido no Brasil e na União Europeia

\begin{tabular}{|l|l|l|}
\hline LMR glifosato & Brasil & União Europeia \\
\hline Produção de café & $1 \mathrm{mg} / \mathrm{kg}$ & $0,1 \mathrm{mg} / \mathrm{kg}$ \\
\hline Produção de cana-de-açucar & $1 \mathrm{mg} / \mathrm{kg}$ & $0,05 \mathrm{mg} / \mathrm{kg}$ \\
\hline Produção de soja & $10 \mathrm{mg} / \mathrm{kg}$ & $0,05 \mathrm{mg} / \mathrm{kg}$ \\
\hline
\end{tabular}

Fonte: Adaptado de Bombardi (2017).

O uso intensivo de agrotóxicos causa em todo o mundo, anualmente, em torno de sete milhões de intoxicações, sendo os países de baixa e média renda responsáveis por, pelo menos, metade delas e por $75 \%$ das mortes por agrotóxicos. No Brasil, entre 2007 e 2014, foram confirmadas mais de 34 mil intoxicações causadas por agrotóxicos. Esses dados mensuráveis são apenas uma parte do problema, uma vez que as doenças crônicas associadas aos agrotóxicos são difíceis de estimar (LONDRES, 2011; ABRASCO, 2016). Estudo realizado por Abreu e Herling (2016) demonstra que, quando se trata de contaminação por agrotóxicos, os agricultores familiares brasileiros, por suas características culturais e socioeconômicas, estão entre os grupos de maior risco de contaminação.

\section{A revolução verde e o agronegócio}

Ao se caracterizar como hegemônico, o agronegócio submete a agricultura à visão mercadológica, sob as "leis do mercado", tornando-a refém das empresas globais. A agricultura, ao ser tratada apenas como um negócio, tem sua sustentabilidade baseada na competitividade e no domínio da natureza. Nesse cenário, os agricultores familiares são considerados como não competitivos; são vistos como praticantes de uma agricultura atrasada e empírica. Para o agronegócio, a sustentabilidade parece ser uma inconveniência, um entrave às suas exigências; pois consideram que se deve buscar o progresso da ciência e o desenvolvimento das sociedades, atendendo, exclusivamente, à vontade e aos interesses do mercado. $\mathrm{O}$ resultado desse modelo é a redução de tudo o que está envolvido em capital e mercadoria, inclusive a natureza, tratada como "capital natural", commodities, serviços ambientais, bionegócios etc.

A segunda revolução agrícola, também conhecida como Revolução Verde, iniciou na década de 1950, nos Estados Unidos da América, e têm sido responsável pela promoção dos sistemas produtivos que se caracterizam por tecnologias mutuamente dependentes, formadas por variedades geneticamente melhoradas com o objetivo de suportar altas doses de fertilizantes solúveis de síntese química industrial, cultivadas em monoculturas mecanizadas de larga escala e protegidas por agrotóxicos. Nos sistemas de criação animal, sua expressão se dá pela seleção genética visando a 
auferir melhores índices de conversão alimentar, elevação da escala produtiva por meio de confinamento e aplicação de produtos químicos (sobretudo antibióticos). Em todos os países nos quais foi adotada a modernização técnica produtivista, atuaram como catalisadores significativos aportes de recursos públicos (CARSON, 1969; CAPELLESSO et al., 2016).

A defesa da Revolução Verde possibilitou um aumento da produção de alimentos, e um custo socioambiental muito elevado. Esse aumento foi justificado porque abria caminhos para a superação da fome. Porém, a Revolução Verde destruiu o modelo tradicional de agricultura que alimentava milhões de pessoas no campo e tem provocado fome nas regiões rurais, porque desestruturou costumes e práticas seculares, eliminando a autonomia dos pequenos agricultores no manejo das sementes (CARSON, 1969). A Revolução Verde também causou uma imensa concentração de terras, sementes e outros elementos utilizados na agricultura nas mãos de algumas grandes empresas de biotecnologia e de agronegócio a serviço da exportação de commodities agrícolas (JUNGES, 2016).

No Brasil, a Revolução Verde iniciou em 1960 e foi impulsionada em meados da década de 1970, a partir da criação do Programa Nacional de Defensivos Agrícolas (PNDA). O PNDA, dentre outras metas, buscava incitar a fabricação e o consumo de agrotóxicos no mercado interno, ação que condicionava a concessão do crédito rural ao uso obrigatório de uma parcela deste recurso na aquisição de agrotóxicos (LIMA; AZEVEDO, 2013). Isso contribuiu para a popularização dessas substâncias químicas, que passaram a ser utilizadas não apenas por grandes produtores, mas também pelos produtores familiares (PORTO; SOARES, 2012).

Ao longo do tempo, a agricultura sofreu diversas mudanças, visto que suas distintas configurações resultaram em complexas transformações que envolveram a produção de alimentos, paisagem, geração de emprego e renda, particularidades sociais nas mais variadas realidades agrárias existentes. Tais transformações foram influenciadas por questões políticas, culturais e socioeconômicas, passando de um modelo primitivo de agricultura para um tecnológico, com o uso abusivo de insumos e aplicação intensiva de tecnologias (THOMAS et al., 2017).

Como resultado dessas mudanças, ao menos $22 \%$ da flora existente no planeta encontrava-se em risco proeminente de extinção no ano de 2011, em decorrência do desaparecimento de seus habitats naturais, por conta do desmatamento para produção de alimentos (PNUMA, 2011). Tais espécies possuem funções importantes para o ecossistema, como destaca Francisco (2015, p. 26):

[...] não basta pensar nas diferentes espécies apenas como eventuais "recursos" exploráveis, esquecendo que possuem um valor em si mesmas. Anualmente, desaparecem milhares de espécies vegetais e 
animais, que já não poderemos conhecer, que os nossos filhos não poderão ver, perdidas para sempre. A grande maioria delas extinguese por razões que têm a ver com alguma atividade humana.

No Brasil, grande parte do desmatamento nas últimas décadas ocorreu com o aval e, de certa forma, com o incentivo estatal. Desde a década de 1940 o Estado tem tentado inserir as regiões Centro-Oeste e Norte do Brasil no mercado externo e, isso, comumente, tem se dado por meio de programas públicos. Maior parte desse incentivo ocorreu através da implantação de grandes projetos extrativistas minerais e vegetais e na produção agropecuária por intermédio de latifúndios (BAMPI et al., 2017).

Nesse contexto, a década de 1960 foi de grande relevância, já que nesse período o governo brasileiro decidiu integrar a Amazônia à economia brasileira. Para tanto, construiu cerca de $60.000 \mathrm{~km}$ de estradas e liberou concessão de crédito e terras e isenção de impostos aos empresários dispostos a investirem em atividades agrícolas na região. Nesse período também foram oferecidos, por fundos internacionais, recursos para investimentos em hidroelétricas, portos e ferrovias, o que resultou no crescimento expressivo da economia, da população e, também, do desmatamento. Por isso, de 1960 a 1980, a Amazônia industrializou-se e apresentou os índices mais elevados de crescimento urbano do país, sem, contudo, elevar a renda da população local (CARVALHO; DOMINGUES, 2016).

Alguns dos efeitos dessas políticas podem ser constatados a partir dos dados disponibilizados pelo Instituto Nacional de Pesquisas Espaciais (INPE, 2013). Tais dados informam que a área total desmatada na Amazônia Legal foi de aproximadamente $755 \mathrm{mil} \mathrm{km}$, o que representa ao redor de $15 \%$ de sua área geográfica. A maior parte do desmatamento, por volta de $570 \mathrm{mil} \mathrm{km}$, ocorreu no período entre 1977 e 2004. Já a taxa anual de desmatamento dos últimos dois anos tem estado próxima de sete mil $\mathrm{km}^{2}$. E, em 2016, foi de $7.893 \mathrm{~km}^{2}, 29 \%$ acima do que ocorreu em 2015, já em 2017, $6.624 \mathrm{~km}^{2}$ (INPE, 2017).

O desafio da crise ambiental é encontrar caminhos para a sustentabilidade socioambiental. $O$ que significa definir soluções que respeitem, por um lado, os ritmos ecológicos da natureza e, por outro, que sejam socialmente adequadas na busca de uma justiça ambiental. Portanto, deve-se ter como axioma que a justiça não será alcançada sacrificando a natureza. Por isso, torna-se necessário adotar princípios indispensáveis para o funcionamento da natureza: ecocentrismo, entropia, trofobiose/homeostase e a construção de uma sustentabilidade socioambiental (JUNGES, 2016).

Para tanto, acredita-se que a prática agrícola pode ser orientada a partir do uso de tecnologia de precisão, sementes revestidas com micróbio, fungos nas raízes das plantas como meios para o equilíbrio ecológico de lavouras agrícolas. Nesse sentido, aponta a agroecologia como uma 
alternativa sustentável para a promoção da saúde e uso racional de recursos naturais.

\section{Tecnologias sustentáveis aplicadas à agricultura}

A Empresa Brasileira de Pesquisa Agropecuária (Embrapa), criada há 43 anos, que atualmente possui 46 unidades de pesquisa distribuídas em todo o Brasil, quatro Laboratórios Virtuais no Exterior (Labex), localizados nos Estados Unidos, na Europa, China e Coreia do Sul e três Escritórios Internacionais na América Latina e África, tem se preocupado com a inovação no campo. Por isso, busca inovar nas áreas de pesquisa e desenvolvimento. E o resultado dessas pesquisas é disponibilizado aos agricultores brasileiros. Uma das Unidades de Pesquisa é a Embrapa Informática Agropecuária que está voltada ao desenvolvimento e à inovação em Tecnologia da Informação e Comunicação (TIC) para agricultura. Esta unidade pauta-se pela visão estratégica nas áreas de agroinformática e bioinformática (MASSRUHÁ; LEITE, 2016).

Em 2011, a Embrapa criou o Laboratório Multiusuário de Bioinformática (LMB), cujo objetivo é incorporar e tornar disponíveis à comunidade científica novas tecnologias para armazenamento, processamento e análise de grande volume de dados. O laboratório também fornece ferramentas especializadas e computação de alto desempenho, para procedimentos computacionais usados na montagem de genomas, análise de metagenomas e de transcriptomas, além de análise de dados de marcadores moleculares e de expressão gênica, desenvolvimento e implantação de recursos computacionais para a criação e administração de bancos e base de dados (MASSRUHÁ; LEITE, 2016).

Também por iniciativa da Embrapa, em parceria com a Universidade Estadual de Campinas (UNICAMP), foi criada a Unidade Mista de Pesquisa em Genômica Aplicada a Mudanças Climáticas (UMIP GenClima). O projeto visa a descobrir e validar genes por meio de transgenia, para a produção de variedades mais adaptadas às condições ambientais exacerbadas por mudanças climáticas (MASSRUHÁ; LEITE, 2016).

Uma tecnologia promissora para gestão do uso de agrotóxico na agricultura é a chamada tecnologia de precisão. Essa tecnologia proporciona o aperfeiçoamento de processos e a redução de custos que ajudam a lavoura a ser produtiva, evitando, por exemplo, desperdícios desnecessários. A tecnologia de precisão é bastante variada, como o uso de sensores de solo, o sensoriamento remoto - que permite, com precisão, informar a localização por meio de fotos de satélites de áreas amplas e dos drones ou veículo aéreo não tripulado (VANT), que ajudam no processo de gestão de lavouras, entre outros (ARTIOLI; BELONI, 2016). 
$\mathrm{Na}$ agricultura de precisão, os drones podem detectar e monitorar grandes áreas quase que em tempo real. Nas imagens geradas, consegue-se identificar onde combater as pragas ou receber reforços de adubação no solo de forma mais específica, o que evita desperdícios e, consequentemente, propicia o aumento da produtividade e a preservação do meio ambiente (ARTIOLI; BELONI, 2016).

A tecnologia possibilitou georreferenciar (gerar informações geográficas) todas as atividades dentro das áreas de produção. A agricultura de precisão pode ser usada no mapeamento dos nutrientes do solo e de pragas, para identificar falhas nas plantações e nas áreas que têm falta ou excesso de água, para padronizar o espaçamento, localizar a presença de ervas daninhas, entre outros detalhes. A partir de uma análise criteriosa das propriedades físicas e químicas do solo é possível mapear as áreas de baixa e alta produtividade, contribuindo com informações para a realocação dos insumos e o controle no uso de agrotóxicos nas áreas demarcadas, evitando os desequilíbrios ambientais (ARTIOLI; BELONI, 2016).

O monitoramento do clima também é fundamental para as atividades agrícolas, devido à grande dependência existente nas condições climáticas. O clima pode influenciar o crescimento, o desenvolvimento e a produtividade das culturas, além de afetar a relação das plantas com insetos e micro-organismos, condicionando isso à ocorrência de pragas e doenças (MASSRUHÁ; LEITE, 2016).

O monitoramento agrometeorológico se efetiva por meio da coleta sistemática e contínua de dados meteorológicos para a elaboração de informações de interesse agrícola. Sistemas que integram as funções de coleta, transmissão e processamento de dados, têm condições de fornecer informações agrometeorológicas atualizadas em tempo quase real. Estão entre as práticas agrícolas que podem se beneficiar com essas informações: o preparo do solo, a semeadura, a adubação, a irrigação, o controle agrotóxico e a colheita. Estimativas de produtividade, de qualidade da produção e da possibilidade de ocorrência de doenças também necessitam de dados meteorológicos (MASSRUHÁ; LEITE, 2016).

O sistema de informações agrometeorológicas denominado Agritempo criado pela Embrapa disponibiliza informações importantes para o zoneamento agrícola de risco climático que é um instrumento de política agrícola e gestão de riscos na agricultura. O sistema pode ajudar na minimização dos riscos relacionados às perdas agrícolas decorrentes de eventos climáticos, identificar a melhor época de plantio das culturas nos diferentes tipos de solo e ciclos de cultivares, para cada região e, ainda, auxiliar minimizando o volume aplicado de agrotóxicos. Com base nas informações do aplicativo, tem-se maior ciência da necessidade ideal dessas substâncias em cada área da lavoura (MASSRUHÁ; LEITE, 2016). 
Além dos mecanismos já citados, existem outros aplicativos desenvolvidos, especificamente para o uso no campo, que abrangem os tamanhos de propriedade e variedades de cultivo. Aplicativos para gestão de processos, gestão de produtos e serviços, gestão de informação, administração financeira e contábil, por exemplo, foram desenvolvidos pela Embrapa Informática Agropecuária (FERRAZ; PINTO, 2017).

O sistema industrial de produção de alimentos também tem se utilizado de Big Datas associados a satélites para monitorar o campo e identificar o histórico de pestes, doenças e do rendimento das colheitas. Com base nesses dados, definem as variedades de plantas, agrotóxicos e fertilizantes que devem ser usados nas plantações. Neste modelo agroindustrial, não existe uma indústria de sementes separada das indústrias de agrotóxicos, fertilizantes ou de máquinas agrícolas (MOONEY, 2018).

Nesse contexto, é comum as empresas do agronegócio alegarem que a transformação tecnológica, como as sementes híbridas nos anos 1960 e 1970, os primeiros organismos geneticamente modificados (OGM) e as novas questões a respeito da agricultura de clima inteligente e da agricultura de precisão resolverão todos os problemas alimentares do mundo. Porém, $70 \%$ da população mundial continua sendo alimentada pelos camponeses e isso não tem mudado ao longo das últimas décadas. Além disso, o sistema de produção camponês costuma ser mais inovador, pois quase metade das pesquisas conduzidas pelo agronegócio se concentra apenas na cultura do milho. No geral, as pesquisas são realizadas em cerca de uma dúzia de grandes culturas em todo o mundo, enquanto que os camponeses trabalham com sete mil espécies diferentes de culturas (MOONEY, 2018).

Alguns fatores se tornam grandes empecilhos ao desenvolvimento e para a aplicação de tecnologias na agricultura familiar, por exemplo, a agricultura de precisão. Dentre os fatores, destacam-se o baixo nível de escolaridade e a falta de conhecimentos mais avançados sobre tecnologias e inovações sustentáveis; afinal, os pequenos produtores costumam ter pouca escolaridade e não estão habituados a utilizar ferramentas de alta tecnologia (FERRAZ; PINTO, 2017). O outro fator que impede o avanço tecnológico em pequenas propriedades é o alto custo das tecnologias, que exige investimentos que não costumam ser viáveis aos produtores (ARTIOLI; BELONI, 2016).

A tecnologia ainda possui barreiras que impedem sua popularização entre os pequenos agricultores. Apenas a tecnologia não é capaz de resolver, sozinha, os problemas que afligem os mesmos. No entanto, para um sistema de produção menos dependente de insumos químicos a tecnologia aliada a outras técnicas como a aplicação de fungos e bactérias para equilibrar o bioma, é uma alternativa viável. Em 1888, o microbiologista holandês Martinus Beijerinck descobriu que as raízes das plantas leguminosas eram 
habitadas por uma bactéria chamada rbizobium, que podia tirar nitrogênio do ar e convertê-lo em uma forma que as plantas pudessem consumir. Desde então, muitos agricultores têm polvilhado rizóbios em pó (i.e. bactérias do solo que possuem habilidade para induzir a formação de nódulos nas raízes e, em alguns casos no caule, de plantas leguminosas, no qual convertem o nitrogênio atmosférico em formas utilizáveis pela planta hospedeira) em plantações de ervilhas, sojas, feijões e outras plantas leguminosas (BROADFOOT, 2016).

Outros micróbios também passaram a ser usados nas lavouras, como biofungicidas e biopesticidas. Mas foi apenas recentemente que novas ferramentas de sequenciamento de DNA permitiram encontrar o vasto e complexo microbioma, conhecido como rizosfera, vivendo dentro e ao redor das raízes das plantas. Em 2012, a Academia Americana de Microbiologia, divulgou o relatório "Como os micróbios podem ajudar a alimentar o mundo". Esta obra demonstra que a exploração desse recurso poderia gerar substâncias que aumentariam a produtividade de qualquer cultura, em qualquer ambiente, de maneira economicamente viável e ecologicamente responsável (BROADFOOT, 2016).

Pesquisadores têm observado como podem beneficiar o fitobioma, ou seja, todos os componentes que envolvem a plantação - plantas, solo, micro-organismos, insetos e clima -, transformando-o em um ambiente menos suscetível às pragas. Essa ideia parte de pesquisas feitas por Karl Ludwig von Bertalanffy, criador da Teoria Geral dos Sistemas, que apresenta a natureza como vasta, interconectada e interdependente (BROADFOOT, 2017).

Os micro-organismos incluem uma grande diversidade de micróbios (vírus, bactérias, fungos, oomicetos e algas), animais (artrópodes, vermes, nematoides e roedores) e outras plantas. $\mathrm{O}$ ambiente consiste no meio em que estão inseridos e seus organismos associados, que são: o solo, o ar, a água e o clima. Interações dentro de fitobiossomos são dinâmicos e têm efeito profundo no solo, nas plantas e na saúde do agroecossistema (PHYTOPATHOLOGICAL SOCIETY, 2016).

Muitas plantas apresentam associações interdependentes com diversos macro e micro-organismos. Essas associações, que ajudam a impulsionar a restauração e a manutenção de solos saudáveis, foram muitas vezes ignoradas; porém, com o avanço tecnológico, algumas ferramentas científicas foram criadas para sondar, de modo detalhado, as redes de fitobioma e gerar conhecimento que pode ser explorado para aperfeiçoar a saúde e a produtividade das plantas (PHYTOPATHOLOGICAL SOCIETY, 2016).

Nos últimos tempos, pesquisadores de empresas agrícolas têm vasculhado o subsolo em busca de micróbios específicos, que podem contribuir 
com a melhoria das plantações. Grandes empresas de agronegócios, como Novozymes e Monsanto, também buscam o pioneirismo de tecnologias nesse segmento. Exemplo disso é a criação de sementes revestidas com micróbios. Essas duas empresas concluíram, em 2016, o maior programa mundial de teste de sementes com micróbios promissores, o qual resultou em uma safra bastante variada de culturas, todas plantadas com sementes que possuíam revestimentos microbianos diferentes (BROADFOOT, 2016).

Em outros casos, há ainda o uso de fungos micorrízicos arbusculares. Quando são associados às raízes das plantas, eles tendem a contribuir com sua nutrição, resultando em menor consumo de fertilizantes minerais e, assim, levam à maximização do equilíbrio ecológico de lavouras agrícolas em uma perspectiva de preservação ambiental e aumento da produção (DURAZZINI; TEIXEIRA; ADAMI, 2016).

Esses fungos destacam-se por formar associações simbiotróficas mutualísticas e se nutrem de substâncias oriundas das raízes das plantas e esse processo beneficia tanto os fungos quanto as plantas. $\mathrm{O}$ processo de penetração do fungo nas células das raízes é determinante na ciclagem de nutrientes e em sua absorção pelas plantas, principalmente de substâncias como fósforo, zinco e cobre para a maioria das plantas e de nitrogênio para as leguminosas (DURAZZINI; TEIXEIRA; ADAMI, 2016).

Com o sequenciamento genético, é possível acompanhar a vida de micro-organismos que vivem no solo. Ele possibilita monitorar como os micróbios mudam no espaço e tempo, como se comportam quando há elevação do uso de fertilizantes ou ocorre uma queda na temperatura. $\mathrm{O}$ sequenciamento genético permite registrar as conversações que microorganismos, plantas e outros organismos travam entre si e decifrar como as comunicações químicas conduzem a produtividade e a saúde dos cultivos (BROADFOOT, 2017).

O conhecimento relacionado ao assunto é bastante amplo e diverso e engloba uma grande quantidade de pesquisadores pertencentes a várias áreas de estudo, como: fisiologistas de plantas, patologistas de plantas e entomologistas, que estudam interações patógenas de pragas, incluindo as vias pelas quais os patógenos e as pragas manipulam as defesas das plantas. Microbiologistas têm detalhado os benefícios das interações que aumentam drasticamente o acesso das plantas à agua e, também, avançam rapidamente na compreensão do microbioma vegetal. Da mesma forma, os cientistas do solo definiram os processos ecossistêmicos críticos para a formação do solo, fertilidade, ciclagem de nutrientes; enquanto criadores de plantas, agrônomos e produtores estabelecem os sistemas de produção que ampliam a produção agrícola. Porém, ainda há muitos desafios, como detalhar o funcionamento da dinâmica das plantas e seus habitats (PHYTOPATHOLOGICAL SOCIETY, 2016). 
Possivelmente, no futuro, sejam fabricadas máquinas que permitirão aos agricultores identificarem os micro-organismos presentes no ambiente, além de outras funções relacionadas à agricultura de precisão, como os níveis de umidade e teor de nutrientes no solo. Tais fatores combinados com dados de safras anteriores, potenciais pragas e previsões climáticas poderão auxiliar no processo de escolha das melhores sementes, nutrientes e micro-organismos para a melhor colheita (BROADFOOT, 2017).

Em relação à plantação utilizando sementes revestidas com micróbios, das empresas Novozymes e Monsanto, os pesquisadores colheram, em 2016, e analisaram os resultados com o objetivo de determinar quais micróbios faziam a diferença. Vários deles se mostraram ineficazes. Mas alguns micróbios aumentaram a produção de milho e soja de modo significativo. Esses primeiros resultados são bastante otimistas; entretanto, os testes de campo devem durar ao redor de sete anos, antes que os resultados sejam tratados como confiáveis. Assim, é necessário aguardar alguns anos e diversos testes antes que se possa considerá-los como alternativa efetiva para combater pragas e aumentar a produtividade agrícola (BROADFOOT, 2016).

Uma das principais vantagens que poderia ser auferida com os produtos agrícolas microbianos seria reduzir, significativamente, o uso de fertilizantes e pesticidas, o que aliviaria os danos que a agricultura causa ao meio ambiente, e com potencial de reduzir os custos e aumentar o rendimento das culturas. A pesquisa pode ser um começo de um movimento ambicioso para substituir a química na agricultura pela microbiologia (BROADFOOT, 2016).

As tecnologias sustentáveis apresentadas anteriormente atendem aos princípios da agroecologia ao preconizar a questão do desenvolvimento sustentável, promoção da saúde, segurança alimentar e nutricional entre outros fatores, como será apresentado a seguir.

\section{Vertentes sustentáveis para a agricultura}

No início do século XX, Albert Howard estabeleceu a base teórica da agricultura orgânica, mostrando a importância da conservação e da fertilidade do solo para o desenvolvimento de plantas sadias e para a formação de um sistema agrícola permanente. Para produzir de modo sustentável seria essencial compreender os princípios básicos sobre a preservação da natureza e o uso do solo de forma adequada para manter a sua fertilidade. A partir dos ensinamentos de Howard, percebe-se que é preciso aprender com a própria natureza a melhor forma de tratá-la (SANTOS et al., 2012).

A agroecologia surge como uma das vertentes da sustentabilidade e tem como diretrizes: desenvolvimento sustentável, promoção da saúde, segurança alimentar e nutricional, além da autonomia do agricultor (SILVA, 
2017). É um modelo de produção agrícola, que respeita os impactos negativos que pode causar ao meio ambiente e à sociedade. $\mathrm{O}$ sistema de produção agroecológico também prioriza a justiça social, o fortalecimento da identidade do agricultor familiar, resgatando suas raízes culturais e autonomia (WARMLING; MORETTI-PIRES, 2017).

A ligação entre sustentabilidade e agroecologia revela a necessidade de reformas estruturais e socioeconômicas, com o intuito de se obter sistemas agrícolas sustentáveis (AZEVEDO, 2017). A relação entre políticas públicas e agroecologia é essencial para garantir programas que viabilizem o desenvolvimento de práticas agrícolas sustentáveis. A produção agrícola deixou de ser uma questão técnica e passou a ser vista como um processo condicionado por dimensões sociais, culturais, políticas e econômicas. É importante toda a dinâmica que envolve a produção agrícola, em cada região, visto que, dessa forma, pode-se ter uma ideia plausível acerca do assunto para cada local (BESSA et al., 2016).

O sistema orgânico não permite o uso de adubos sintéticos, tampouco de agrotóxicos, caracterizando-se pelo comprometimento dos agentes envolvidos na preservação da natureza, priorizando a utilização de formas sustentáveis e racionais dos recursos naturais. E, nessa utilização racional de exploração da terra, são empregados métodos tradicionais com tecnologias ecológicas (SANTOS et al., 2012).

O sistema orgânico reproduz e aperfeiçoa os processos naturais por meio da utilização efetiva dos recursos locais e da reciclagem de nutrientes e de energia. As ações agroecológicas tornam os agricultores menos dependentes das grandes empresas agrícolas. Os fertilizantes industriais podem ser substituídos por restos de plantas, estrume e árvores, que proporcionam ao solo os nutrientes essenciais. Em vez de agrotóxicos, os cultivos diversificados mantêm as pragas sob controle. As plantações ocorrem em meio das plantas que repelem os insetos indesejados ou que atraem aqueles que são benéficos para o sistema (SANTOS; GLASS, 2018).

Devido à importância da agricultura orgânica, o governo brasileiro instituiu a Lei no 10.831, de 23 de dezembro de 2003, que define os parâmetros legais para o sistema orgânico de produção. Com base nessa lei, é possível afirmar que um sistema de produção orgânico possui as seguintes finalidades: I) ofertar produtos saudáveis isentos de contaminantes intencionais; II) preservar a diversidade biológica dos ecossistemas naturais e recompor ou incrementar a diversidade biológica dos ecossistemas modificados em que se insere o sistema de produção; III) incrementar a atividade biológica do solo; IV) promover um uso saudável do solo, da água e do ar e reduzir ao mínimo todas as formas de contaminação desses elementos, que possam resultar das práticas agrícolas; V) manter ou incrementar a fertilidade do solo em longo prazo; VI) reciclar resíduos 
de origem orgânica, reduzindo ao mínimo o emprego de recursos não renováveis; VII) basear-se em recursos renováveis e em sistemas agrícolas organizados localmente; VIII) incentivar a integração entre os diferentes segmentos da cadeia produtiva e de consumo de produtos orgânicos e a regionalizar a produção e comércio desses produtos; IX) manipular os produtos agrícolas com base no uso de métodos de elaboração cuidadosos, com o propósito de manter a integridade orgânica e as qualidades vitais do produto em todas as etapas (SANTOS et al., 2012).

A agricultura orgânica busca produzir alimentos em áreas em que a produção e o solo não sofreram quaisquer ações de fertilizantes ou agrotóxicos, ou que foram devidamente tratadas, caso tenham recebido essas substâncias no passado, de modo que não contaminem a produção orgânica. Este tipo de agricultura pode proporcionar diversas vantagens ao meio ambiente, como: interação animal-vegetal, manutenção e preservação de nascentes e mananciais hídricos, proteção ambiental, respeito à biodiversidade. Ademais, suas atividades não contaminam a natureza com o uso indiscriminado de agrotóxicos (SANTOS et al., 2012).

\section{Considerações finais}

A efetividade de discussões políticas sobre os níveis de componentes agrotóxicos utilizados na agricultura brasileira é essencial para a proposição de regulamentação e práticas que resultem em um agroecossistema produtivo e ecologicamente responsável.

$\mathrm{O}$ uso em grande escala de agrotóxicos com o desenvolvimento genético trouxe melhorias para a capacidade dos cultivos e incremento na oferta de alimentos. No entanto, a permissividade do uso de substâncias químicas parece gerar problemas imensuráveis para a flora e fauna.

Como evidenciado neste trabalho, no Brasil, é premente pensar em ações orientadas para a redução do uso de fertilizantes e pesticidas de natureza química e, ao mesmo tempo, promover o uso, por exemplo, de produtos agrícolas microbianos. $\mathrm{O}$ investimento em microbiologia para a agricultura com sementes revestidas de micróbios é promissor considerando que, em algumas culturas, têm-se o aumento da produção, segurança alimentar e mitigação dos efeitos causados ao meio ambiente.

Os programas governamentais voltados para a sustentabilidade no campo com base na agroecologia parecem ser uma alternativa possível quando aliados a intenções políticas, econômicas e sociais que viabilizem o desenvolvimento de práticas agrícolas sustentáveis. Nesse sentido, acreditase que olhar para as mudanças necessárias no campo, de modo particular para a agroecologia de forma perene, como apontou Bessa et al. (2016), e não como ação isolada e descoordenada, pode levar à efetividade de uma produção agrícola sustentável. 
É relevante refletir sobre os impactos que o registro e a comercialização de substâncias ativas banidas em outros países, como os da União Europeia, proporcionam às indústrias de agrotóxicos brasileiras. No Brasil, o ecossistema tem sido alterado por práticas inadequadas do uso do solo, contaminação de nascentes, mananciais hídricos e lençóis freáticos, bem como por riscos à saúde humana gerados por consumo de alimentos saturados de componentes agrotóxicos.

Como apontado neste estudo, atributos e ações sustentáveis para a produção agrícola na União Europeia indicam que o caminho para um sistema de produção agrícola sustentável está condicionado, por exemplo, às práticas de produção menos degradantes, como o estabelecimento de Programas governamentais expressivos para a preservação ambiental e de incentivo à agricultura diversificada.

No Brasil, a concessão de isenções fiscais e tributárias para a comercialização de alguns agrotóxicos que são banidos na União Europeia denota a pouca importância dada às implicações para a saúde humana e para o bioma brasileiro. $\mathrm{O}$ modelo praticado na União Europeia pode ser o ponto de partida, mas é necessário ir além, de modo que o uso de insumos químicos, sobretudo, agrotóxicos, seja abolido ou uma opção apenas em casos extremos.

É de interesse repensar singularidades de um modelo agrícola sustentável pautado nos princípios da agroecologia e aliados à tecnologia de precisão para o equilíbrio do ecossistema e da saúde humana. Torna-se urgente pensar em um sistema que una interesses de produtores agrícolas, grandes empresas e governo em uma tentativa de mitigar impactos gerados pela exploração de recursos naturais para a garantia do bem-estar social das gerações futuras.

\section{Referências}

ASSOCIAÇÃO BRASILEIRA DE SAÚDE COLETIVA (ABRASCO). Dossiê Abrasco: um alerta sobre os impactos dos agrotóxicos na saúde. Rio de Janeiro: Abrasco, 2016.

ABREU, P. H. B.; HERLING, G. A. O agricultor familiar e o uso (in)seguro de agrotóxicos no município de Lavras/MG. Revista Brasileira de Saúde Ocupacional, v. 41, n. 18, p. 1-12, dez. 2016.

ALTIERI, M. A. Green deserts: Monocultures and their impacts on biodiversity. Food and Agriculture Organization of the United Nations, 2009. Disponível em: http:/www.fao.org/docs/eims/upload/276609/monocultures.pdf. Acesso em: 11 mar. 2017.

ARTIOLI, F.; BELONI, T. Profile diagnosis of users of drones in Brazilian Agribusiness. Revista iPECEGE, v. 2, n. 3, p. 40-56, 2016.

ASSIS, R.; ROMEIRO, A. R. Agroecologia e agricultura orgânica: controvérsias e tendências. Desenvolvimento e Meio Ambiente, v. 6, p. 67-80, jul./dez. 2002. 
AZEVEDO, R. A. B. Sucessão ecológica, entropia e o modelo autonomiaheteronomia para análise dos sistemas agrícolas. Redes, v. 22, n. 2, p. 70-91, maio/ ago. 2017.

BAMPI, A. C. et al. Expansão da fronteira agrícola capitalista no Baixo Araguaia Brasileiro (MT). Estudios Socioterritoriales, v. 21, p. 29-45, enero/junio 2017.

BARRETO, L. M. E. C. et al. Pesticides in the propolis at São Saulo State, Brazil. Acta Scientiarum Animal Sciences, v. 34, n. 4, p. 433-436, 2012.

BESSA, M. M. et al. Agroecology, sustainability and the need of movements agroecological become public policy. Desafios, v. 2, n. 2, p.181-197, jan./jun. 2016.

BOFF, L. O cuidado necessário. Rio de Janeiro: Vozes, 2012.

BOMBARDI, L. Geografia do uso de agrotóxicos no Brasil e conexões com a União Europeia. São Paulo: FFLHC - USP, 2017.

BRANTSAETER, A. L. et al. Organic food consumption during pregnancy and Hypospadia and Cryptorchidism at birth: The Norwegian Mother and Child Cohort Study (MoBa). Environmental Health Perspectives, v. 124, [s. n.], [s. p.], 2015.

BRASIL. Ministério Público Federal. Nota de Repúdio ao Projeto de Lei no 3.200/2015. 2016. Disponível em: http://www.mpf.mp.br/pgr/documentos/ Nota_repdio_3.200.pd. Acesso em: 16 mar. 2018.

BRASIL. Ministério da Agricultura, Pecuária e Abastecimento. Agropecuária puxa o PIB de 2017.2018. Disponível em: http://www.agricultura.gov.br/noticias/ agropecuaria-puxa-o-pib-de-2017. Acesso em: 18 maio 2018.

BROADFOOT, M. Microbes to seeds could boost crop production. Scientific American, jan. 2016. Disponível em: https://www.scientificamerican.com/article/ microbes-added-to-seeds-could-boost-crop-production/. Acesso em: 18 maio 2018.

BROADFOOT, M. Construindo uma safra melhor. Scientific American, v. 176, p. 68-75, 2017.

CAPELLESSO, J. A. et al. Ambiguidade de referenciais tecnológicos da ação pública no meio rural. Desenvolvimento e Meio Ambiente, v. 36, p. 167-187, abr. 2016.

CARSON, R. A primavera silenciosa. São Paulo: Editora Melhoramentos, 1969.

CARVALHO, T. S; DOMINGUES, E. P. Projeção de um cenário econômico e de desmatamento para a Amazônia Legal brasileira entre 2006 e 2030. Nova Economia, Belo Horizonte, v. 26, n. 2, p. 585-621, maio/ago. 2016.

CASTRO, J. P. S. Agronegócio e sustentabilidade: a atuação do estado brasileiro e as consequências do uso de agrotóxicos. 2018. 135 f. Dissertação (Mestrado em Sustentabilidade) - Programa de Pós-Graduação em Sustentabilidade, Pontifícia Universidade Católica de Campinas, Campinas, 2018.

DELGADO, G. Reestruturação da economia do agronegócio. In: STEDILE, J. P. (Org.). A questão agrária no Brasil. São Paulo: Expressão Popular, 2013. p. 57-88.

DURAZZINI, A. M. S.; TEIXEIRA, M. A.; ADAMI, A. A. V. Quantificação de esporos de fungos micorrízicos arbusculares (FMAs) em solo sob diferentes cultivos de cafeeiros. Revista Agrogeoambiental, Pouso Alegre, v. 8, n. 4, p. 83-91, dez. 2016. 
EUROPEAN PARLIAMENTARY RESEARCH SERVICE (EPRS). Human health implications of organic food and organic agriculture. Bruxelas: European Parliament, 2016.

FERRAZ, C. O.; PINTO, W. F. Tecnologia da Informação para a Agropecuária. RECoDAF, Tupã, v. 3, n. 1, p. 38-49, jan./jun. 2017.

FRANCISCO, P. Carta Encíclica Laudato Si: sobre o cuidado da casa comum. São Paulo: Paulinas, 2015.

INSTITUTO NACIONAL DE PESQUISAS ESPACIAIS (INPE). Metodologia para o Cálculo da Taxa Anual de Desmatamento na Amazônia Legal. 2013. Disponível em: http://www.obt.inpe.br/ prodes/metodologia_ TaxaProdes.pdf. Acesso em: 28 abr. 2018.

INSTITUTO NACIONAL DE PESQUISAS ESPACIAIS (INPE). INPE estima $6.624 \mathbf{~ k m 2}$ de desmatamento por corte raso na Amazônia em 2017. 2017. Disponível em: http://www.obt.inpe.br/OBT/noticias/INPE-estimadesmatamento-por-corte-raso-na-Amazonia-em-2017. Acesso em: 17 dez. 2017.

JUNGES, J. R. Ecological-ethical principles of socio-environmental sustainability: the economic and agricultural case. Revista Iberoamericana de Bioética, n. 1, p. 1-13, 2016.

LEAHY, J.; SCHIPANI, A. Brazil: Rainforest pays the price for the country's crisis. 2018. Disponível em: https://www.ft.com/content/971f03aa-f9e0-11e79b32-d7d59aace167. Acesso em: 11 jan. 2018.

LIMA, A. M.; AZEVEDO, C. F. Impactos culturais e socioambientais deixados pela Revolução Verde na região do brejo paraibano - Brasil. Revista Verde, Mossoró, v. 8, n. 5, p. 116-123, dez. 2013.

LONDRES, F. Agrotóxicos no Brasil: um guia para ação em defesa da vida. Rio de Janeiro: Articulação Nacional de Agroecologia, 2011.

MARIYONO, J. et al. Quantity and monetary value of agrochemical pollution from intensive farming in Indonesia. Management of Environmental Quality: An International Journal, v. 29, n. 4, p. 759-77, june 2018.

MASSRUHÁ, S. M. F. S.; LEITE, M. A. A. Agricultura Digital. RECoDAF, Tupã, v. 2, n. 1, p. 72-88, jan./jun. 2016.

MENDONÇA, M. L. O papel da agricultura nas relações internacionais e a construção do conceito de agronegócio. Contexto Internacional, Rio de Janeiro, v. 37, n. 2, p. 375-402, maio/ago. 2015.

MOONEY, P. R. Multinacionais ampliam controle da cadeia alimentar por meio do monopólio de dados. 2018. Entrevista à Emilly Dulce. Disponível em: https://www.brasildefato.com.br/2018/07/16/multinacionais-ampliam-controleda-cadeia-alimentar-por-meio-do-monopolio-de-dados. Acesso em: 10 ago. 2018.

OLIVEIRA, C. O.; PAULA, M. H. Violações socioambientais e direitos humanos no Brasil. Goiânia: UEG, 2016.

OLIVEIRA, T. E. et al. O agronegócio da água. Revista em Agronegócio e Meio Ambiente, v. 9, n. 4, p. 785-802, out./dez. 2016. 
PELAEZ, V. et al. A (des)coordenação de políticas para a indústria de agrotóxicos no Brasil. Revista Brasileira de Inovação, Campinas, v. 14, n. esp., p. 153-178, jul. 2015.

PHYTOPATHOLOGICAL SOCIETY. Phytobiomes: A Roadmap for Research and Translation. 2016. Disponível em: http:/www.phytobiomes.org/ Roadmap/Documents/ PhytobiomesRoadmap.pdf. Acesso em: 26 set. 2018.

PIMENTEL, D. et al. Economic and environmental threats of alien plant, animal, and microbe invasions. Agriculture, Ecosystems and Environment, v. 84, p. 1-20, 2001.

PROGRAMA DAS NAÇÕES UNIDAS PARA O MEIO AMBIENTE (PNUMA). Rumo à economia verde: Caminhos para o Desenvolvimento Sustentável e a Erradicação da Pobreza. 2011. Disponível em: https://www. unenvironment.org/admin/publicacoes/texto/1101-GREENECONOMYsynthesis_PT_-_online_version.pdf. Acesso em: 22 out. 2017.

PORTO, M. F.; MILANEZ, B. Eixos de desenvolvimento econômico e geração de conflitos socioambientais no Brasil: desafios para a sustentabilidade e a justiça ambiental. Ciência \& Saúde Coletiva, Rio de Janeiro, v. 14, n. 6, p. 1983-1994, 2009.

PORTO, M. F.; SOARES, W. L. Modelo de desenvolvimento, agrotóxicos e saúde: um panorama da realidade agrícola brasileira e propostas para uma agenda de pesquisa inovadora. Rev. Bras. Saúde Ocupacional, São Paulo, v. 37, n. 125, p. 17-50, 2012.

SANTOS, J. O. et al. Organic farming and the sustainability. Revista Verde, Mossoró, v. 7, n. 5, p. 59-65, dez. 2012.

SANTOS, M.; GLASS, V. Altas do agronegócio: fatos e números sobre as corporações que controlam o que comemos. Rio de Janeiro: Fundação Heinrich Böll, 2018.

SILVA, J. S. Agroecologia e a ética da inovação na agricultura. Redes, Canoas, v. 22, n. 2, p. 352-273, maio/ago. 2017.

TACHIZAWA, T.; MENDES, G. Como fazer monografia na prática. 12. ed. Rio de Janeiro: Editora FGV, 2008.

THOMAS, E. R. et al. Interactive comment on "Review of regional Antarctic snow accumulation over the past 1000 years". Climate of the Past, v. 13, p. 14911513, 2017.

VAZ, P. A. B. Direito Ambiental e os Agrotóxicos - Responsabilidade Civil, Penal e Administrativa. Porto Alegre: Livraria do Advogado, 2006.

VILAÇA, M. L. C. Pesquisa e ensino: considerações e reflexões Márcio Luiz Corrêa Vilaça. E-scrita, v. 1, n. 2, p. 59-74, maio/ago. 2010.

WARMLING, D.; MORETTI-PIRES, R. Sentidos sobre agroecologia na produção, distribuição e consumo de alimentos agroecológicos em Florianópolis, SC, Brasil. Interface, Botucatu, v. 21, n. 62, p. 687-98, 2017.

Recebido em: 18/12/2018.

Aceito em: 21/06/2019. 


\title{
SUSTAINABLE ALTERNATIVES TO THE INTENSIVE USE OF AGROCHEMICALS IN BRAZILIAN AGRICULTURE
}

\begin{abstract}
The excessive use of pesticides in agriculture, based on the choice of substances, quantity and quality does not always take into account the damages generated for health, society and ecosystems. This work aims to discuss the permissive use of agrochemicals in Brazil, to point out the consequences generated for the ecosystems and to indicate alternatives that are less harmful to the environment and health. Based on the methodology of the bibliographical research the work allows to indicate alterantivas that can subsidize more sustainable conditions for Brazilian farming. Precision technology and agroecology applied to agricultural production minimize negative impacts on the environment and society. The results suggest that the effectiveness of political discussions on the levels of agrochemical components used in Brazilian agriculture is essential for proposing regulations and practices that result in a productive and ecologically responsible agroecosystem. However, the permissiveness of the Brazilian State regarding the use of agrochemicals seems to generate immeasurable problems for the flora and fauna. In Brazil, the granting of tax and tax exemptions for the commercialization of some agrochemicals that are banned in the European Union shows the little importance given to the implications for human health and the Brazilian biome.
\end{abstract}

Keywords: Brazilian state. Farming. Use of agrochemicals. Sustainable alternatives. Agroecology.

\section{ALTERNATIVAS SOSTENIBLES AL USO INTENSIVO DE AGROTÓXICOS EN LA AGRICULTURA BRASILEÑA}

\begin{abstract}
Resumen
El uso excesivo de agrotóxicos en la agricultura, partiendo de la elección de sustancias, cantidad y calidad no siempre lleva en consideración los daños generados para la salud, la sociedad y los ecosistemas. Este trabajo objetiva discutir sobre el uso permisivo de agrotóxicos en Brasil, señalar consecuencias generadas para los ecosistemas e indicar alternativas que sean menos nocivas para el medio ambiente y la salud. A partir de la investigación bibliográfica, este ensayo permite indicar alternativas que pueden subsidiar condiciones más sostenibles para la agricultura brasileña. La tecnología de precisión y la agroecología aplicadas a la producción agrícola minimizan los impactos negativos para el medio ambiente y la sociedad. Los resultados sugieren que la efectividad de discusiones políticas sobre los niveles de componentes agrotóxicos usados en la agricultura brasileña es esencial para la proposición de reglamentación y prácticas que resulten en un agroecosistema productivo y ecológicamente responsable. Sin embargo, la permisividad del Estado brasileño en cuanto al uso de sustancias agroquímicas parece generar problemas inmensurables para la flora y la fauna. En Brasil, la concesión de exenciones fiscales y tributarias para la comercialización de algunos agrotóxicos que son prohibidos en la Unión Europea denota la poca importancia dada a las implicaciones para la salud humana y para el bioma brasileño.
\end{abstract}

Palabras clave: Estado brasileño. Agricultura. Uso de agrotóxicos. Alternativas sostenibles. Agroecología. 